\author{
Poesía en lenguas negadas. \\ Una nota sobre la traducción al mixe \\ de un poema de Mahmud Darwish \\ Poetry in Denied Languages. \\ A Note on the Translation to Mixe of a Poem \\ by Mahmud Darwish \\ YASNAYA ELENA AgUILAR \\ Colegio Mixe
}

\begin{abstract}
RESUMEN: A partir de la experiencia de traducir al mixe el poema Discurso del "Indio". El penúltimo ante el "Hombre Blanco", la autora reflexiona sobre la posibilidad de construir puentes entre lenguas sin Estado, sobre la dimensión política de la escritura de poesía en lenguas negadas, y sobre la relación entre traducción y resistencia.
\end{abstract}

ABSTRACT: From the experience of translating the poem Discurso del "Indio". El penúltimo ante el "Hombre Blanco" to Mixe, the author reflects on the possibility of building bridges between languages without a state, on the political dimension of writing poetry in denied languages, and on the relationship between translation and resistance.

PALABRAS ClAVE: Mahmud Darwish, traducción, resistencia.

KEYWORDS: Mahmud Darwish, translation, resistance.

RECIBIDO: 8 de febrero de 2017 - ACEPTADO: 18 de abril de 2017

Interpretatio, 2.2, 2017, pp. 57-63 


\author{
YASNAYA ELENA AGUILAR \\ Colegio Mixe
}

\title{
Poesía en lenguas negadas. Una nota sobre la traducción al mixe de un poema de Mahmud Darwish
}

Dice el extraño palabras extrañas, y cava en la tierra un pozo para enterrar al cielo.

DISCURSO DEL "INDIO"

Queda poco por descubrir en el mundo para una parte de la humanidad. La mirada de los que han descubierto las islas y los valles, las selvas y los desiertos, los árticos y los polos está cansada. Una parte de la humanidad se jactó de descubrir los recovecos de la superficie de este planeta y después, la repartió. En este reparto, los pueblos sujetos a la mirada escrutadora y descubridora de los que narran la historia quedaron encapsulados dentro de entidades jurídicas, que no naciones, llamadas países, Estados que controlan los territorios que creen haber descubierto. Los pueblos como el palestino, el mixe en México o el ainu en Japón, sufren y combaten los efectos de una superficie terrestre repartidada en aproximadamente 200 entidades jurídicas que controlan un determinado territorio y que se relacionan con ella de una sola manera posible: como una posesión. Los miles de pueblos del mundo que sufren las consecuencias de este, relativamente, nuevo orden, son llamados, en muchos casos, pueblos indígenas: pueblos sin Estado, pueblos sin ejército, pueblos de 
territorios despojados, pueblos de lenguas negadas, pueblos que no son Estados, pueblos que no son reconocidos como naciones.

El surgimiento de los Estados supuso la creación de imaginarios homogeneizadores a través de un discurso nacionalista estatal: un Estado equivale a una sola nación, un país tiene una sola identidad, una sola cultura, incluso, una sola lengua. Las lenguas que no se usan en los discursos oficiales de los agentes de cada uno de los estados del mundo han sido silenciadas y abiertamente combatidas. En un contexto dividido en estados, según datos del Catálogo de Lenguas Amenazadas de la Universidad de Hawaii, cada 15 días muere una lengua. Según cálculos de la UNESCO, en los próximos cien años morirá aproximadamente la mitad de las lenguas del mundo. Esto es inédito en la historia de la humanidad, es consecuencia de un mundo que no admite otra manera de existir como nación que no sea la del Estado, con ejército, con marina, con Constitución y leyes escritas, con una sola lengua, con poder y con la lucha por el poder.

La diversidad lingüística dentro de un Estado es la negación misma de su homegeneidad y por eso ha sido tan combatida por los estados modernos. La negación del Estado francés a reconocer en su Constitución la existencia de las muchas lenguas que se hablan en su territorio, es un claro ejemplo de cómo enunciar el mundo en lenguas no estatales tiene claras implicaciones políticas. Las campañas castellanizadoras en México son otro ejemplo; desde la creación del Estado mexicano hasta la actualidad, ha habido un dramático decremento en la proporción de hablantes de lenguas indígenas: a principios del siglo XIX, aproximadamente $65 \%$ de la población hablaba alguna lengua indígena, mientras que ahora, sólo lo hace $6.5 \%$ de la población. En la actualidad, hablar una lengua indígena se ha convertido en una declaración contra las prácticas monolingües y lingüicidas del Estado mexicano; escribir en una lengua indígena, se convierte en resistencia política; hacer poesía en lenguas indígenas, es ya una declaración de principios; traducir a un poeta palestino como Mahmud Drawish a lenguas como el mixe, el zapoteco o el chinanteco, supone enunciar juntos, pueblos sin Estado, la existencia de otras maneras posibles de ser nación, otras maneras posibles de relacionarnos con la tierra, otras maneras posibles de hacer poesía. 
Hace años que mi nación es sólo lenguaje MAHMUD DARWISH

El pueblo palestino y el pueblo mixe, la nación palestina y la nación mixe, están hermanadas por una negación: la negación de la forma peculiar en la que se relacionan con un territorio que les ha sido arrebatado; un territorio que ha sido estatizado por otros; un territorio, una naturaleza, tratados como recursos naturales de los que puede disponer el Estado. En ambos casos, la negación de la autonomía relaciona los reclamos de los pueblos indígenas de México y del pueblo palestino.

En este contexto, traducir un poema de Mahmud Darwish, el ya legendario poeta de la Palestina ocupada, a una lengua como el mixe, establece, desde el mismo acto, pactos poéticos enunciados desde lugares negados. En el caso del pueblo mixe, la nación también es lenguaje, un lenguaje combatido por medio de castigos físicos y sicológicos; desde las escuelas hasta las cárceles; desde los espacios familiares hasta los espacios públicos. Las lenguas indígenas son lenguas que, desde la enunciación oficial, han sido renombradas y degradadas como dialectos.

La tarea de traducir a Mahmud Darwish comienza entonces a construirse en medio de un territorio ideológico cargado ya de implicaciones, de entendidos y de supuestos. Los dados ya están cargados. No podemos obviar la importancia de traducir a los poetas sin Estado, a lenguas sin Estado. No se puede dejar de apuntar la trascendencia de ese acto mismo, más allá del éxito de la traducción; la sola existencia de las palabras de Darwish, revestidas en la gramática y la semántica de una lengua como el mixe, dice algo, crea puentes entre territorios cognitivos fuera de las enunciaciones en lenguas privilegiadas y atravesadas por el discurso estatal. Aún más, el poema de Darwish traducido al mixe se titula Discurso del "Indio". El penúltimo ante el "Hombre Blanco" y, a lo largo de sus siete apartados, aborda la relación de las naciones sin Estado, las naciones colonizadas con un territorio, con una naturaleza ya poseída por otros.

Una de las preguntas más importantes durante el proceso de traducción consistió en determinar cómo traducir la palabra "indio" al mixe, lengua en la que no existe un equivalente satisfactorio. En mixe, 
es posible encontrar una palabra que nos designa (ayuuk jä'äy) y, otra, que designa a los no-mixes, sean éstos zapotecos, palestinos o daneses (akäts). ¿Cómo encontrar un equivalente que nombre a las naciones del mundo sin Estado? ¿Era realmente necesario hallar un equivalente? Las respuestas a estas preguntas fueron múltiples y se fueron resolviendo a lo largo del texto, estrategias para nombrar lo que puede considerarse un indio en tierras mixes.

Por otra parte, uno de los puentes más importantes sobre el que caminó el proceso de traducción, tuvo que ver con la relación con la tierra, la naturaleza y el territorio. En México, desde el punto de vista legal, es posible relacionarse con la tierra de tres maneras: mediante la propiedad privada, mediante el régimen ejidal o mediante la propiedad comunal. La mayoría de los pueblos mixes nos relacionamos con el territorio mediante la propiedad comunal, nadie posee legalmente la tierra y los rituales para marcar la relación con ella muestran, a pesar de los procesos de evangelización, que es una relación fuertemente simbólica e integral. No existe una sola manera válida de relacionarse con un territorio, no existe una sola manera válida de imaginar un territorio ni de establecer redes con lo que lo habita.

Para defender una única manera de relacionarse con el territorio, se han desatado guerras; en nombre de una sola manera de relacionarse con la tierra, se han completado despojos. La diversidad de los modos de relacionarse con el mundo y sus entes se ve reflejada también en la diversidad de las maneras de nombrar el mundo. En muchas lenguas no occidentales, la tierra, la naturaleza y sus elementos, no pueden llevar marcas morfológicas de posesión, puesto que se entiende que nadie puede poseer el aire, el agua o el territorio. Lo que se puede hacer es crear una compleja red de rituales y significados que nos permitan relacionarnos con él: peticiones para disculparnos con la tierra al herirla para abrir una carretera, peticiones para la lluvia o rituales para la abundancia. La relación con la tierra y la naturaleza necesita articularse en significados y los significados poéticos son privilegiados.

Por estas razones, traducir "El discurso del "Indio"” de Mahmoud Darwish a lenguas indígenas se convierte en una declaración de principios, en una proclama de los pueblos sin naciones: las naciones de 
lenguas negadas podemos articular, tanto en Palestina como en la Sierra Mixe, que somos un elemento más del territorio, que no podemos poseerlo, que el territorio nos posee y que existen múltiples maneras, físicas y poéticas, para relacionarnos con la tierra y sus elementos.

Las consecuencias ambientales de negar estas múltiples formas de relación y de simplificar los ritos de relación con la naturaleza son terribles y hay evidencia de ello. Por todo esto, traducir las palabras de Darwish al territorio del mixe sirve como un nuevo ritual, el ritual de la traslación poética para reafirmar que no, la tierra no puede ser poseída y las naciones sin Estados, así lo reclamamos, desde nuestras lenguas negadas que, a pesar de todo, siguen siendo territorios cognitivos sin colonizar. 